\title{
Plan S Point-Counterpoint: Discussing the Plan Together
}

* Originally shared on the ISMTE website at https://www.ismte.org/page/2019NACONFPLANS

At the ISMTE 2019 North American Meeting, Rick Anderson, Associate Dean for Collections \& Scholarly Communication at the J. Willard Marriott Library at the University of Utah and Micah Vandegrift, Open Knowledge Librarian at North Carolina State University Libraries, discussed their different opinions regarding some of the finer points of Plan S. They prepared responses for 10 questions for the meeting but were only able to respond to some of them in person. The following is the full Q\&A that they prepared for the meeting, with references added.

\section{Is Plan S necessary?}

Rick: This question begs a prior one, which is: "Necessary for what?" If your goal is to achieve universal open access (OA) - in other words, a scholarly-communication ecosystem in which there is no such thing as paid access to content-then Plan S (or other mandates just like it) is absolutely necessary. On the other hand, if you want to preserve or even increase choice and diversity among access models in the scholarly communication ecosystem, then Plan S isn't necessary, though that doesn't mean you have to be opposed to it: you might see Plan $S$ as one acceptable option among many, and as a model that can coexist with others. Or you might see it as unnecessarily and even unacceptably constraining and coercive for authors.

This concept of choice and diversity is one that's probably going to keep coming up during our conversation today. There's a really fundamental issue here that we need to deal with, and that is: what do we want the scholarly communication ecosystem to look like? There are some who want it to consist of nothing but open access; in other words, they don't want anyone to ever have to pay for access to scholarly content, and they want no restrictions whatsoever on the reuse and repurposing of that content. Others-though vanishingly few of them-are opposed to open access entirely. Still others, like me, think OA is wonderful and that its continued growth and development should be encouraged, but don't see it as the only morally acceptable model or set of models, and think that reasonably priced toll access can also be acceptable. So again, when we ask the question "Is Plan S necessary?" it depends entirely on what your ultimate goal is. If you insist on universal $O A$, then of course Plan $S$ is necessary. If you don't insist on universal OA, then it's not, though that doesn't mean you have to oppose it.

Micah: Yes. Plan S is necessary because funders want to advance more quickly toward a more open research ecosystem. It is also necessary, although perhaps unfair, as a tool for funders (policymakers) to leverage their goals against the goals of publishers. l'd also say that we could talk less about Plan S specifically, and more generally about Plan S as an example of what is necessary in higher education. What Plan S represents, that I feel is necessary now, is a 
concrete marker that the publishing system is changed. It is an infusion of new energy into a stale discussion about best ways forward. The necessity of things like Plan S, or like the University of California breaking its Elsevier big deal, is the acknowledgement that there are no more excuses for being behind the curve. We ARE on a pathway toward open, and each stakeholder group_-publishers (of all varieties), researchers, funders, policymakers, and universities - will adapt. Plan $S$ is one of many roadmaps for how adaptation will occur.

I also strongly believe that much of the fallout from Plan S sidestepped a basic point of order; the funders have every prerogative to put whatever earmarks on the funding that they prefer. When I give my kids $\$ 5$ for allowance, I am clear that they cannot spend it on candy and ice cream. So, if the funders, who are responsible to policymakers who are responsible to the good people of the Netherlands, France, Norway, etc., if the funders believe that Plan S is necessary, it really doesn't matter what my opinion is as a librarian. I understand the dismay and furor that might cause for researchers, but in an age where transparency is shaking industry after industry to the core, it feels brash and unwise to expect cash to keep flowing into your lab's account without a hint of fiduciary responsibility to the public.

In summary, Plan S is necessary because open is the near future, it provides funders with leverage against the publishers, and because the funders so willed it.

\section{To what degree are the ideals of Plan S achievable?}

Micah: It depends. If the "ideals of Plan S" are to inspire a quicker advance toward full OA, I think that has been effectively achieved in that ISMTE decided to have a plenary session on it at their North American conference. We need to make a clear distinction between "Is Plan S a successfully implemented funder open access policy?" and "Does Plan S achieve increased momentum toward a more open future for research publications?" We have yet to see if it will be successfully implemented, but as the European Union moves from its Horizon 2020 to its Horizon Europe funding scheme, I believe that much of the heart of Plan S principles will be achieved either through EU policy or national policy. And, let's opine for a moment that Plan S fails and cOAlition $S$ is disbanded-there is nothing to say that national funding bodies won't continue to strengthen and impose Plan S-like measures. No one wants to make this about sticks, but if you don't get your publications in PubMed, the National Institutes of Health will act to achieve compliance.

A different question l'd like to address is how are the principles of Plan S achievable? Build, utilize, and maintain interoperable open infrastructure for scholarly publishing. And by "infrastructure," I mean not just the technical systems and content management platforms, but also the (principle 6) strategies, policies, and social norms. I strongly believe that initiatives like Invest in Open or the Global Sustainability Coalition for Open Science Services are one step on the path toward a functional publishing ecosystem with transparency and community governance built in. I think the preprint boom is a step along this path, the library publishing 
boom is a step along the path, and the re-recognition of institutional and other repositories is a significant step on this path.

Rick: The ideals of Plan S are clearly and concisely laid out on the cOAlition S website, 1 and the pithiest summary of them is the sentence, "No science should be locked behind paywalls." It's important to note that Plan S's goal isn't to free up only the science funded by the members of cOAlition S-the coalition is saying that no science at all, and in fact no scholarship at all, should be behind paywalls. This is made clear by another of the coalition's stated intentions: to "accelerate the transition to a scholarly publishing system that is characterised by immediate, free online access to, and largely unrestricted use and re-use of scholarly publications." 2 What would it take to achieve that ideal? Well, it would take one of two things: either universal and voluntary acceptance of the proposition that all scholarly publications must be OA, or (failing that) universal mandates that take non-OA choices away from authors, institutions, and publishers. Universality is a tall order, and I can't think of any situation in which it has been achieved without external coercion.

Now, is coercion a bad thing? Obviously, it depends. All of us accept and support varying levels of coercion in many areas of our lives, depending on what we believe is right and wrong and depending on what we think is a proper balance between choice and constraint. Speed limits are coercive, as are restrictions on gun ownership, and regulations that limit the way drugs can be sold. l'd be willing to bet that every one of us in this room agrees that some degree of coercion is appropriate in those contexts. Agreeing or disagreeing with an example of coercion doesn't make it more or less coercive; it only amounts to an opinion on whether that instance of coercion is acceptable.

But getting back to feasibility: the kind of external coercion that Plan S represents is eminently achievable in systems where there's a high degree of central control-which is exactly what you have in European countries, where all higher education tends to be public and where there are centralized ministries of education that have a significant ability to dictate policies to their institutions. In these contexts, the ideals of Plan S are quite a bit more achievable than they are in, say, the United States, where we have no centralized ministry of public higher education and where we also have a vigorous community of private higher education. In an environment like ours, the ideals of Plan S face significant challenges because it's very hard to tell faculty and institutions what to do.

Of course, there's nothing to stop individual funders from adopting Plan S-type programs and principles, and a couple of big American ones-the Gates and Ford Foundations-actually did so before Plan S existed. But so far, government funders have not done so, and neither have most private funding organizations. So I guess what l'd say is that the ideals of Plan S are eminently and obviously achievable at limited scale_-but whether those ideals can be achieved globally is more questionable.

\section{How will Plan S affect society publishers?}


Rick: There are two fundamental problems with this question: the first is that any answer to it is going to be speculative-mainly because whatever impact it has on societies will be indirect. Plan S imposes direct requirements on researchers and authors, not on societies, so much of the impact on societies will be in the form of knock-on effects rather than direct ones, and that makes the effects harder to predict.

The other problem with this question is that you can't answer it without knowing the degree to which a particular society's members or journals fall within the scope of Plan S's influence. As things stand now, a society that depends on revenue from a suite of humanities journals is less likely to be affected than, say, a society of chemists or engineers, because its members are less likely to be supported by funds from cOAlition $S$ members.

That said, the potential impact of Plan S on society publishers is one of the issues often raised by those who have other concerns about Plan $S$ as well, while those who are in favor tend to characterize any expression of concern as fear-mongering. But just because any answer to this question is necessarily speculative doesn't mean that all speculation is equally valid.

Speculations can be based more or less on logic and on more or less real information about things that we currently know.

But obviously, when it comes to publishers generally, Plan $S$ has the greatest potential to cause trouble for the smaller nonprofit houses (most of which are societies) and it poses less of a threat to the big commercial ones, who have lots of pre-built infrastructure and who publish high-demand journals and can often command higher article processing charge (APC) prices. For example, the Lancet could probably flip to OA next week, and would be able to command a huge APC, because publishing in the Lancet can be a career-making win for a researcher. Big commercial publishers are also the ones who can respond to Plan S's requirements by quickly setting up new and reasonably high-quality OA journals. The nonprofit society publishers are less likely to have that capability. And when societies have raised these concerns, the message of Plan S's architects has been "tough luck. Get with the program." The irony is that the harder you make it for society publishers to do business independently, the more likely you make it that they'll license their journals to big publishers like Elsevier or Wiley.

Micah: I don't know how Plan S will affect society publishers, and since I am not working in publishing, l'd hate to force an uninformed position. I, like many l'm sure, am anxious to see the product of Wellcome Trust, UK Research and Innovation (UKRI), and the Association of Learned \& Professional Society Publishers (ALPSP) partnership to employ the Information Power consulting firm "to explore a range of potential strategies and business models through which learned societies can transition to Open Access and adapt and thrive under Plan S." I echo Allison Muddit's worry that in a race to be seen as Plan S compliant, it is possible that society publishers will approach commercial publishers for workflow and distribution support, as well as a financial safety net. 
On the flipside, my hope for Plan S-wary society publishers is that in fact they will find closer alignment with libraries who support publishing activities (and/or university presses!) and begin the long process of disentangling from a print/commercial legacy toward an academy-owned and community-governed model. One example we have of this is the LingOA consortium, which is working under their "Fair Open Access Publishing Model," whereby the responsibilities for publishing are shared between a publishing services provider (Open Library of the Humanities in this case), researchers, and libraries. We also have the SCOAP3 (Sponsoring Consortium for Open Access Publishing in Particle Physics) model to harken to as a longer-term experiment in flipping a sub-field to open. I would also like to see societies start to leverage preprint repositories, overlay journals, and open peer review more effectively as this transition evolves.

Society publishing is central to the future of scholarly communication. Plan S may give it a kick in the pants to make some hard decisions, and I sincerely hope that libraries and university presses can grow to meet the needs of society publishers.

\section{How can the U.S. academic publishing ecosystem adapt to and align with Plan S-ish ideals?}

Micah: We have to agree on one thing - that the democratization of knowledge and access to the scholarly record is the goal. And, we have to agree on a second thing-that this changes everything else. And, we have to agree on another thing - this work will take time, but we should expect one another to be responsible and careful along the path. Finally, and more importantly, we have to agree that this is all about researchers - not libraries, not funders, not publishers.

I think that "read and publish" deals are one way that we are attempting to adapt and align. Also, I am a big believer in library publishing as a model for researcher-aligned, principled publishing. I am learning to be a coalition builder. But, l'd like to see a bold plan of action from the United States. In my early career, that was the grueling work of faculty-led, library-inspired, repository-focused OA policies at the university level. The straw that will break the camel's back is when the University of Utah announces that it will privilege OA and scholarly sharing in tenure and promotion decisions. We're already seeing job ads moving in this direction, asking researchers to speak to their practices of reproducibility and openness.

So, if we want to align with the most idealistic of the Plan S ideals-to quicken the pace toward $\mathrm{OA}$ and to fundamentally revise the incentive and reward system of research-I see two simple paths forward. The U.S. publishing ecosystem can

- double down on repository-fueled openness and authors rights retention and

- $\quad$ work with faculty governance to adapt tenure and promotion guidelines to account for work that is public, digital, and open. 
Rick: Again, this question begs another one: we're asking how this system can adapt to and align with Plan S-ish ideals before establishing that the U.S. academic publishing ecosystem should adapt to those ideals. There's a lot of disagreement among the people and organizations who make up that ecosystem as to whether something like Plan $S$ would actually be a good idea here. Many of us think OA is great. But being fully in favor of OA isn't the same thing as being in favor of making OA universally mandatory, or even making it mandatory on a funder or institutional basis. In other words, if you ask American scholars and scientists the isolated question "Are you in favor of making scholarship freely available?", the great majority will say yes. But if you ask, "Do you believe that OA is the only morally acceptable model of access to scientific scholarship and that it should be made mandatory?", I think the great majority are going to say no. Authors' ambivalence toward OA has been documented repeatedly in many different surveys and studies, 3,4 and the pervasiveness of that ambivalence is actually demonstrated by the growing number of mandatory OA policies in places where such policies are possible. If authors weren't ambivalent about OA, you wouldn't need mandates. So then the next question becomes: should it be up to authors, or should this choice be made for them by others?

And I guess this is where it becomes necessary to bring up the issue of academic freedom. Academic freedom isn't a legal doctrine, but it's a longstanding and deeply cherished value in the United States, and the generally accepted definition of it is the one laid out in a 1940 statement by the American Association of University Professors (AAUP), which includes the following: "Teachers are entitled to full freedom in research and in the publication of the results, subject to the adequate performance of their other academic duties." $5 \mathrm{Now}$, in the context of OA there's some debate as to whether "full freedom in publication" means only freedom to publish or freedom to choose whether, how, and where to publish, and this is something l've actually urged the AAUP to clarify. (Unfortunately, they've declined to do so.) But in the meantime, I do think it's kind of hard to reconcile telling a researcher how and where they may and may not publish with the idea of "full freedom in publication," and given the well-documented ambivalence of many scholars and researchers about OA, I suspect that if you were to poll all of America's scholars you'd probably find that there's little enthusiasm for the idea of being told how and where to publish.

All of that being said, it's also worth pointing out that Plan $S$ is actually quite late to the game-the U.S. academic publishing ecosystem has been moving in the general direction of Plan S's ideals for 20 years or so. But again, here it's important to be clear on what Plan S's ideals are: they are to make OA universally mandatory. The U.S. system will continue to move gradually closer and closer to that ideal over time, but l'd be very surprised if OA ever became universally mandatory here. There is simply too much diversity of viewpoint about OA here, too much decentralization, and too much support-both philosophical and structural-for letting scholarly authors make their own publishing choices.

\section{Are there any unintended consequences that we can anticipate?}


Rick: The growth of mirror journals is certainly one consequence that I think Plan S's architects didn't intend, and one that will grow to the degree that Plan S-type mandates grow. Plan S's implementation requirements attempt to prevent their funds from being used to support mirror journals, but I suspect those efforts will only lead to mirror journals being renamed or reconfigured to the minimum degree necessary.

Another unintended consequence will be increased difficulty for international research projects. If two researchers are working on the same project but operating under different publishing rules, that's going to be problematic. Obviously this is less of an issue for grant funding and more of an issue to the degree that institutions adopt Plan S-style mandates, though even in terms of grant funding Plan $S$ is probably going to make it harder for European researchers to collaborate with, say, Chinese or American colleagues.

Another is the impact of open-licensing requirements on scholars working in disciplines in which the product of their work is not only scientific results and facts, but also creative work and expression. Providing blanket permission to the world at large to create and sell derivative versions of a symphony you've composed, or a cultural analysis you've written, or a theory you've developed is potentially very different from providing that permission with regard to a purely factual scientific report.

And, of course, there's the differential impact on researchers from less-developed economies and less well-resourced institutions who don't have access to APC funds. And it's all well and good to say, "Well, Plan S tells the journals that they shouldn't charge APCs in those cases," but we need to remember that many journals are themselves poorly resourced and don't have the wherewithal to provide high-quality publishing services at no charge. There are lots of journals that don't charge APCs, but most of the ones authors want to publish in do.

But if Plan S and similar mandates really do take off globally, I think the biggest unintended consequence will be a huge proliferation in APC-funded Gold OA journals. I know that's not what Plan S's architects necessarily intended-Plan S does technically support multiple funding models-but we're talking about unintended consequences here, and I think there's a much lower likelihood that a critical mass of toll-access journals will start allowing unembargoed Green deposit than that they'll simply switch from toll-access to APC-funded Gold, which of course has the effect not of eliminating toll barriers, but simply of moving them from one place to another. The subscription model places a toll barrier between the reader and the content, while the APC model places a toll barrier between the author and the publishing service. The large-scale shifting of costs from readers to authors and funders is probably the single biggest likely unintended consequences of Plan S.

Micah: There are many unintended consequences that have been spelled out in great detail in think pieces, tweets, statements and manifestos, editorials, and articles. Most of them that I have seen and read have been negative, so l'd like to throw some optimism into the mix. 
One unintended consequence could be that researchers respond in great force and with action within their own disciplines. For example, what if bioinformaticians decided that $100 \%$ OA as quickly as possible was their goal? There could be field-shaking shifts in publishing practices overnight if a group was coordinated and also supported by their professional association. The assumption of Plan $S$ is that funders have the next power play. I'm watching with great anticipation to see what a scholar-led, discipline-specific OA agenda would look like.

Another unintended consequence, if Plan S succeeds and the general European Research Area goes full $100 \%$ OA by 2022 , is that European research could skyrocket in global impact, unseat the United States, Germany, China, and India, and the European Union makes good on its "Open Science, Open Innovation, Open to the World" scheme. Then, we have to contend with the fact that "open" actually works, funders control it, and the larger ecosystem hinges around compliance and monitoring.

Another unintended consequence that we should expect is that the very nature of scholarship as we know it, brand-new, original ideas first seen in a single "prestigious" publication, could fade. If, suddenly, 3-6\% of the world's published research is available online openly licensed, remixes, mashups, and shuffle playlists will be the norm. l've been reading a bit recently about the challenges of authors in the global south to break into and engage with northern/western scholarly channels. One issue is the language barrier. If 3-6\% of the world's research literature can be translated and adapted to diverse cultural contexts without having to leave your passport and $\$ 35$ at the Copyright Clearance Center desk, imagine the possibilities.

One potential unintended consequence that I don't want to admit-could the publishers' pool their (our) money and fund research themselves? So, I could be a Polish researcher looking for

funding, see the Plan S requirements from my national funding body, hear about a pilot program from a large commercial publisher with many high impact journals that I want to publish in, and opt out of national funding to take a check from Big Publishing.

\section{What principles of Plan S can we agree on?}

Micah: Generally, I agree with the plan in principle, and with many of the comments about the high bar that it sets. I have rewritten the principles with a few caveats that I believe offer a strong step forward and increase the feasibility of the success.

1. Authors should retain copyright and grant a license to publish; no mandated specific license.

2. Researchers should develop robust criteria and requirements for the services that high-quality OA journals, OA platforms, and OA repositories must provide.

3. Funders should support open infrastructure, coordinated by partnerships with academic societies, libraries, and university presses. 
4. OA publication fees should not be paid by the researcher.

5. OA publication fees should be transparent.

6. Funders, governments, universities, research organizations, libraries, academies, and learned societies should harmonize their strategies, policies, and practices.

7. Open access for different scholarly formats (articles vs. chapters vs. books vs. software, etc.) needs different plans; the guideline line should be "as open as possible, as closed as necessary."

8. Hybrid journals have had their day. Thank you, next.

9. Funders should monitor and ensure compliance for research they fund.

10. Let the work stand for itself, not the delivery packaging, nor the file format, nor the name listed as the corresponding author, etc. Good work is good work regardless of journal impact factor.

Rick: This will be my shortest answer, given that Micah and I were invited here specifically because we don't agree about Plan S!

But that doesn't mean we don't agree on any of Plan S's underlying principles.

For one thing, there's no question that Micah and I agree that OA is a good thing. All other things being equal, I would love for everyone in the world to have free and unfettered access to all scholarly content. The problem, obviously, is that all things are never equal and the question will always be "Is there a way to accomplish that goal that will optimally balance cost and benefit?" There are OA programs that I believe are well worth the cost, and others that I don't believe to be worth the cost. Plan S is one of the latter; but that doesn't mean I disagree with Micah and other Plan $S$ supporters that $O A$ is a good thing in itself.

I think Micah and I would also agree that funders have every right to adopt and implement Plan $S$ if they wish. It's their money, and it's their prerogative to attach whatever stipulations they wish (within the law, obviously) to the use of that money. Micah and I disagree on whether adopting and implementing Plan $S$ is the right thing to do, but we agree that funders are fully within their rights to do it.

\section{Do we even want $100 \%$ open access?}

Rick: Since I don't believe that the ends always justify the means, my answer has to be that it depends on how we achieve it. If we end up with $100 \%$ OA because all scientists and scholars come to universal agreement that $O A$ is the only acceptable model, then I think that would be 
great. If we achieve $100 \%$ OA by making it universally mandatory, thus forbidding all other models, I don't believe it will be worth it.

I guess another way of putting this is that I prefer democracy to more authoritarian styles of governance, and in the context of scholarly communication democracy means that the people who make up the ecosystem get to make meaningful choices about how the system is set up and run. If the scholarly communication ecosystem should be run on broadly democratic principles, then that means that all members of the system get a voice, ideas and principles get discussed and debated in a respectful and above-board way, and then people get to vote with their feet by choosing between different options.

Now, I want to be very clear about this: I'm not a libertarian, and I'm not saying that everyone has to have perfect freedom to do whatever they want in any circumstance. And I'm definitely not saying that free markets are the solution to every problem-especially in scholarly communication. There are some things that I think should be forbidden, and there are some things that I think should be required. But I am saying that I think there's such a thing as reasonable freedom of choice in this arena, and that reasonable freedom of choice is important. Of course, part of what creates controversy around these issues is the fact that there's a lot of disagreement between people as to what constitutes "reasonable freedom of choice."

One thing that I get asked a lot when I bring up the issue of academic freedom and reasonable freedom of choice is "Well, what about publishers that require copyright transfer in order to publish in their journals? Isn't that just as coercive as funders or institutions requiring OA publication?" And my answer to that is no, because different entities in the scholarly communication ecosystem have different levels of coercive power with regard to authors. A funder or an institution has much greater power over an author than an individual journal does, so I have more concern about a funder or an institution exerting coercive power over an author than I do about a journal doing so. 6

But that being said, I actually don't think publishers should require copyright transfer. I think they should require only a limited publication license.

Micah: Open is a global advancement toward equity of access, diversity of thought, and inclusion of voices. There are many challenges in the world, and I strongly believe that the desire for open access to scholarly literature is not one we should be arguing about anymore. The worst thing we can do at this point is to give our friends and neighbors outside of the higher education/publishing industry any reason to question the value of what we do inside the university. In my opinion, open access to research literature and products can help reinforce the public trust in expertise within the academy. But, access must also be combined with more thorough means and modes of communicating scholarly ideas to the interested public.

Quoting Kathleen Fitzpatrick, because I can't not in anything I ever write or say on this topic, "We [in the humanities] often resist opening our work to the broader public, fearing the 
consequences of such openness-and not without reason. The public at times fails to understand our work, and, because the content of the work seems as though it ought to be comprehensible... The problem, of course, is that the more we close our work away from the public, and the more we refuse to engage in dialogue with them, the more we undermine that public's willingness to fund our research and our institutions. Closing our work away from the public, and keeping our scholarly conversations private, might protect us from public criticism, but it can't protect us from public apathy, a condition that is, in the current economy, far more dangerous. This is not to say that such openness doesn't bear risks, particularly for scholars working in controversial areas of research, but it is to say that only through open dialogue across the walls of the ivory tower will we have any chance of convincing the broader public, including our governmental funding bodies, of the importance of our work." (On Open Access Publishing, 2011)

\section{How will Plan S affect researchers and authors?}

Micah: I polled a few listservs at NC State on this question, and the single response I got was "journal choice." While I was in the Netherlands last year, a lot of the fear and worry around Plan $S$ that I heard was about recruitment of post-docs and graduate students to countries under Plan S requirements. Much virtual ink was spilled over what Plan S means for academic freedom, and I will direct you to the work of J. Britt Holbrook, a philosopher at New Jersey Institute of Technology, for much more cogent analysis and arguments than I could represent. A question that was posed in a Twitter spat was, is it better to change attitudes or behaviors? From my personal perspective, I will always work to advise and advocate for new attitudes, but when someone else (funder) imposes a behavior shift that compliments my work, I'm not complaining.

The greatest impact I believe Plan S will have on researchers is forcing them to contend with the commercialization and ownership of their labor. Research is expensive, it is a privilege to have a resource pool to tap from, but how will one balance personal ethics and principles against the sale of their ideas? The cool thing is, I think humanities monographs already have a great model of dealing with this - they partner with a university press, often a non-profit organism affiliated with an institution of higher education, and sometimes they earn a small check for royalties. There is a seeming balance between the sale of ideas and the feel-good moment of contributing back to public knowledge. There are lots of challenges in monograph publishing, but also quite a few ongoing experiments on how to evolve that system with partnerships between libraries, university presses, and researcher-led organizations.

So, if the greatest impact of Plan S on researchers is that they have to think harder about what they own and what personal principles they want to enforce on their own work, then l'd call Plan $\mathrm{S}$ a success. Seventy-five percent of my job is letting researchers know what they own and how to wisely utilize those rights. 
Rick: The answer to this question isn't as speculative as it has to be with regard to societies, because as I mentioned before, Plan S affects researchers and authors directly and societies indirectly.

It's important to remember that relatively few authors are actually directly affected by Plan S. As of today, cOAlition S consists of 19 funding agencies, all but one in Europe and the UK.7 Estimates vary somewhat, but right now Plan S members control roughly $\$ 8.8$ billion in research funds8 - that's not a small amount of money, but it affects a small minority of researchers worldwide.

For those researchers, however, the biggest impact of Plan S will be a dramatic narrowing of publishing options. At this point, only about $15 \%$ of legitimate scholarly journals are compliant with Plan S,9 and many OA repositories don't meet the strict Plan S guidelines either, 10 so depending on how rigorously compliance is monitored and enforced, researchers may experience fairly sudden and dramatic impacts on their day-to-day work when Plan $S$ is fully implemented.

Another impact it will have is an increase in the difficulty of international research collaboration, which I mentioned briefly before. If you're a Swedish medical researcher and your research funding comes from a member of cOAlition $\mathrm{S}$, and you want to work on a project with an American or Chinese or Russian collaborator, if that other researcher is aware of Plan $S$ you can reasonably expect that they're going to say "Hang on, will we be able to publish this in the right journal?" And if they don't become aware of Plan S until you've finished the project and the time has come to publish, you can reasonably expect that your collaborator will say, "Hang on a minute, why can't we submit our article to the Lancet or Cell?"

You could argue that one benefit of Plan $S$ for researchers and authors is that it makes their work more broadly available for reading and reuse. But in fact, Plan S doesn't in itself create any new opportunities for open publishing that wouldn't exist in the absence of Plan S. It hasn't created any new platforms or journals; it requires its grantees to make use of already-existing platforms and journals that the authors could have chosen to use on their own if they felt those were the right venues for their work. What Plan $S$ does is close off publishing options, not create new ones. This will change, however, if Plan S actually does end up leading to an explosion in the number of APC-funded Gold OA journals as I suggested it might.

However, arguably one positive impact of Plan S will be that it will raise awareness of scholarly communication issues among researchers. Those who haven't been paying attention to the various issues and controversies around toll access, OA, journal pricing, etc., will find their consciousness raised as they're required to confront and deal with them by funding requirements. What conclusions they'll come to as their consciousness is raised is, of course, an open question. But then, their opinions only matter to the degree that they have freedom of choice. 
How does Plan S instigate funder policy discussions here in the United States, and how can we prepare for or inform those discussions?

Rick: I haven't found much evidence that Plan S has, in fact, instigated much in the way of policy discussions in the United States, except among librarians and publishers and others who don't actually set funding policies.

Interestingly, shortly after Plan S was rolled out in late 2018, its primary architect and spokesman, Robert-Jan Smits, announced that he was coming to the United States to meet with federal officers and encourage them either to join Plan $S$ or to adopt similar policies. A news report at the time quoted him as saying that he was coming to the United States for "business, not chit-chat." 11 Well, the business didn't amount to much and he went home empty-handed. From what l've heard from second-hand sources, the response he got was basically, "We already have a federal public-access program in place, and we think it works just fine, thanks."

Now, this doesn't mean that there hasn't been any uptake at all of Plan S here. As I mentioned before, the Bill \& Melinda Gates Foundation has formally joined cOAlition S, though it's worth pointing out that the Gates Foundation already had an OA policy in place that was in line with Plan S principles, so for them, joining the coalition didn't mean making any real changes to its policies or stances - it just meant saying, "Sure, we're on board." To my knowledge, no other private or public funder in our country has signed on to cOAlition $S$, for reasons including those we discussed earlier.

But have there been discussions of Plan S among other American funding bodies? I've looked for evidence of it and haven't found any, though that doesn't mean it hasn't happened and Micah might be aware of conversations that I'm not. I looked for public evidence that foundations like Mellon, Ford, Pew, Lilly, Kellogg, and Robert Wood Johnson had engaged in any kind of public discussion about Plan S, and found nothing-though, again, it's possible that such discussions are happening behind closed doors.

Interestingly, I can't even find evidence that uptake of Plan S is being discussed by the Open Society Institute, which was the convener of the Budapest Open Access Initiative.

But let's say such discussions are going to take place in the future. How can we prepare for or inform them? I think one of the most important things that could be done would be to prepare a rigorous analysis of the costs and benefits of Plan S, publish that analysis in a white paper, and make it freely available to anyone interested-especially to any funding or oversight body that is considering adoption of Plan $\mathrm{S}$ or a similar mandate.

Micah: Originally, I thought that Plan S was a huge step ahead of the United States. But, then I remembered the OSTP Directive (2013). Plan S is a national funder OA mandate. We already have those (public access) in the United States for 17 federal funding agencies $(\mathrm{NIH}, \mathrm{DOD}$, NOAA, NASA, Energy, Transportation, etc.). The turnover in national administration in 2016, the 
subsequent advancement of an anti-open agenda, and a two-year delay in naming a new Director of the White House Office of Science and Technology Policy (Director Kelvin Droegemeier (Jan 2019)) were distractions at best and deeply harmful regressions at worst. There are many more important policy issues that we should advocate for in the United States right now.

But, if I have to answer the question-what we don't have in the United States that I observed in Europe are functional and efficient compliance and monitoring mechanisms with the exception of the NIH. So, librarians, university presses, society and association publishers, funders, etc., should come together and outline a transparent, academy-owned and governed system for increasing compliance with our existing federal funder open policies for publications and data. I don't want to reignite the SHARE vs. CHORUS debate, but if the NSF started to call folks to the carpet on their data sharing policy, there would be a lot of frantic researchers posting lots of huge files on Dropbox, or publisher's PDFs on ResearchGate. We could work together to get ahead of that.

Dr. Droegemeier commented directly on Plan S, saying, "One of the things this government will not do is to tell researchers where they have to publish their papers. That is absolutely up to the scholar who's doing the publication. There's just no question about that. We certainly strongly support open access, and have since the Holdren memo came out in 2013. We want timely access to the information, to data, and to publications and so on. That hasn't changed at all." So, it seems that a U.S. policy perspective is that research should be open, and we'll suggest where to deposit it, but we will never get in the middle of the publishing process.

\section{What (if any) differences in impact will Plan S create for the STM (scientific, technical, and medical) and HSS (humanities and social science) disciplines?}

Micah: Parroting much of the discussion already online, the timeline to implementation must be different, CC-BY needs to be negotiable, and the scaffolding of a research concept from idea to book needs to be evolved.

I would like to see an OA plan for the humanities and social sciences that lowers the need for long embargos by beginning to move to more early release of core research ideas in HSS. More frequent, open circulation of electronic theses and dissertations (ETDs), syllabi, posters, "talks," preprints, gray literature, and articles, would, in my humble opinion, decrease the need for long embargo periods to allow the ideas to percolate through the field. This is where the uptick in "scholarly sharing" is really interesting. The act of releasing a research output into the public aside from, before, and/or in spite of "publishing," by utilizing a platform (Zenodo, SocArxiv, figshare, Humanities Commons), scholarly social network (Academia, ResearchGate), or a documentation tool (Open Science Framework, github, wiki), feels like a lower barrier possibility for humanistic scholarship, where open interventions occur at various points throughout the research spectrum. 
An ideal humanities Plan S-ish-compliant workflow might look like this:

- $\quad$ Receive funding

- Teach

- Research

- Write and publish article in Open Library of the Humanities sponsored journal (funded by library contributions and cOAlition $\mathrm{S}$ infrastructure grant)

- Write and publish a review article (not currently supported under Plan S); post to a humanities general (Humanities Commons) or discipline specific repository (PhilPapers) with infrastructure funding from Coalitions

- Write monograph

- $\quad$ Publish monograph OA with Brill (\$10k) using funding from UKRI

- $\quad$ OA book available in the Directory of Open Access Books (DOAB) and OAPEN

Rick: As things stand, Plan S's most direct impact will be in the hard sciences, because that's where the cOAlition $S$ funders make the most grants. In the U.K., where national funding is provided both directly to researchers through the Research Councils and indirectly for infrastructure through the Quality Research program, the impact on HSS researchers may be felt more keenly.

This means that some of the strongest objections to Plan S have actually been registered by those least likely to be directly affected by it-for example most recently, by the British Academy-at least as things stand now.

But it's important to remember that while the language of Plan S originally talked about "science," at some point between its initial rollout and its current version, that word got quietly changed to "scholarship" (and on the "Why Plan S" page, you can now see explicit mention of the fact that whenever cOAlition S materials say "science," they mean the word to include the humanities). That change has very large implications, and requiring OA publication really does have different impacts on humanists and scholars in arts and literature than it does on those working in more traditionally data-driven fields. For example, if you're a historian, the new facts that you may uncover in the course of your research represent only a part of your scholarly product. Your argumentation, your individual line of reasoning, and the way you express your arguments are all integral parts of your scholarly product. Requiring you to grant a CC BY license or the equivalent (thus allowing anyone in the world to adapt your work, translate it, or create other derivatives without your permission) is going to have a different impact on you than 
it will on a physics researcher whose scholarly product consists fundamentally of the reporting of data. This isn't to say that physicists don't engage in interpretation or exercise creativity: it's only to say that there are meaningful and significant differences from field to field in the roles that interpretation and personal expression play, and those differences have real implications for the impact of open-licensing requirements.

One of the common objections to OA mandates that we hear from scholars in HSS fields is that since so much of the work they do isn't grant-funded, APC costs affect them much more personally and directly than they do researchers who are working on grants. But in the case of Plan S this particular objection doesn't apply, because Plan $S$ requirements only apply where grant funds are received from members of cOAlition $\mathrm{S}$ - and those funders have all agreed that paying APCs is an acceptable use of their funds.

Again, though, it's important to remember that funders who focus on HSS fields have just as much right to put conditions on the use of their money as funders in STM fields do-so again, objecting to Plan S-type restrictions here would not be a matter of saying "they don't have a right" but rather of saying "even though they have the right, I don't think it's the right thing to do."

This work is licensed under a Creative Commons Attribution 4.0 International License.

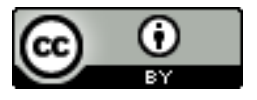

\section{Biographies and Conflict of Interest Statements}

Rick Anderson is the Associate Dean for Collections \& Scholarly Communication at the J. Willard Marriott Library, University of Utah. ORCID: 0000-0002-1623-7067. E-mail: rick.anderson@utah.edu. Twitter: @looptopper. Rick serves as an unpaid member of the advisory boards of numerous publishers and service providers, including biorXiv, JSTOR, Elsevier, and Oxford University Press. He has no financial interest in any company or firm in the field of scholarly communication.

Micah Vandegrift is the Open Knowledge Librarian at North Carolina State University, Raleigh. ORCID: https://orcid.org/0000-0001-8429-7697. E-mail: mlvandeg@ncsu.edu. Twitter: @micahvandegrift. Micah declares no affiliations that could be perceived as posing potential conflicts of interest in relation to this presentation.

\section{Rick Anderson References}

1) Plan S: making full and immediate open access a reality. Accessed August 12, 2019. https://www.coalition-s.org. 
2) COAlition S appoints Jisc expert to accelerate open access. Accessed August 12, 2019. https://www.coalition-s.org/coalition-s-appoints-jisc-expert/.

3) Carol Tenopir et al. Imagining a gold open access future: attitudes, behaviors, and funding scenarios among authors of academic scholarship. College \& Research Libraries 2019; 78 (6):824-843.

4) Skelton V. Author attitudes to open access: global survey of thousands of authors reveals regional and subject differences. Accessed August 12, 2019.

https://www.infotoday.eu/Articles/Editorial/Featured-Articles/Author-attitudes-to-Open-Access-93 010.aspx.

5) 1940 statement of principles on academic freedom and tenure. Accessed August 12, 2019. https://www.aaup.org/report/1940-statement-principles-academic-freedom-and-tenure.

6) Anderson R. Open access, academic freedom, and the spectrum of coercive power. Accessed August 12, 2019. https://scholarlykitchen.sspnet.org/2018/11/05/open-access-academic-freedom-and-the-spectru m-of-coercive-power/.

7) Funders that have endorsed Plan $S$ and are jointly working on its implementation. Accessed August 12, 2019. https://www.coalition-s.org/funders/.

8) News \& views: potential impacts of Plan S. Accessed August 12, 2019. https://deltathink.com/news-views-potential-impact-of-plan-s/.

9) Else H. Radical open access plan could spell end to journal subscriptions. Nature 2018;561:17-18.

10) Revised Plan S and repositories. Accessed August 12, 2019.

https://www.coar-repositories.org/news-media/revised-plan-s-and-repositories/.

11) Else H. Architect of bold European open-access plan heads to Washington to garner US support. Nature 2018;562:174.

\section{Micah Vandegrift References}

An Interview with OSTP Director Kelvin Droegemeier. (2019, April 30). Retrieved July 5, 2019, from https://www.aip.org/fyi/2019/interview-ostp-director-kelvin-droegemeier

Aut, S. C. D. author. (2019). Concerns remain over European open-access proposal. https://doi.org/10.1063/PT.6.2.20190628a 
Becerril-García, A. (n.d.). AmeliCA vs Plan S: Same target, two different strategies to achieve Open Access. Retrieved July 9, 2019, from

http://www.amelica.org/en/index.php/2019/01/10/amelica-vs-plan-s-mismo-objetivo-dos-estrateg ias-distintas-para-lograr-el-acceso-abierto/

Plan S and the Transformation of Scholarly Communication: Are We Missing the Woods? Retrieved July 29, 2019, from The Scholarly Kitchen website:

https://scholarlykitchen.sspnet.org/2019/06/03/plan-s-and-the-transformation-of-scholarly-comm unication-are-we-missing-the-woods/

Guest Post: Plan S and Humanities Publishing. Retrieved July 5, 2019, from The Scholarly Kitchen website:

https://scholarlykitchen.sspnet.org/2019/07/02/guest-post-plan-s-and-humanities-publishing/

Cambridge University Press issues public statement on Plan S. (n.d.). Retrieved January 6, 2019, from Cambridge University Press website:

https://www.cambridge.org/about-us/news/cambridge-university-press-issues-public-statementplan-s/

Comment: ARL Feedback on Plan S Open Access Implementation Guidelines. (n.d.). Retrieved July 5, 2019, from Association of Research Libraries website:

https://www.arl.org/news/arl-comments-on-plan-s-open-access-implementation-guidelines/

DOAJ. (2018, September 11). The 10 Principles of Plan S. Retrieved September 13, 2018, from News Service website: https://blog.doaj.org/2018/09/11/the-10-principles-of-plan-s/

Harvard Library and MIT Libraries provide recommendations for Plan S implementation | MIT Libraries News. (n.d.). Retrieved January 17, 2019, from

https://libraries.mit.edu/news/harvard-library/29052/

Haug, C. J. (2019). No Free Lunch-What Price Plan S for Scientific Publishing? New England Journal of Medicine, 380(12), 1181-1185. https://doi.org/10.1056/NEJMms1900864

Innovations, 101. (2019, June 15). Nine routes towards Plan S compliance - updated. Retrieved July 9, 2019, from Innovations in Scholarly Communication website:

https://101innovations.wordpress.com/2019/06/15/nine-routes-towards-plan-s-compliance-updat ed/

Keeping an eye on the horizon | Research Information. (n.d.). Retrieved July 5, 2019, from https://www.researchinformation.info/news/keeping-eye-horizon 
Khoo, S. (n.d.). Increasing open access publications serves publishers' commercial interests. Retrieved July 5, 2019, from The Conversation website:

http://theconversation.com/increasing-open-access-publications-serves-publishers-commercial-i nterests-116328

Koulocheri, E. (n.d.). Plan S: A European Open Access Mandate. Retrieved January 7, 2019, from OpenAIRE website: https://www.openaire.eu/plan-s-a-european-open-access-mandate

Kramer, B. (2018, December). UU Plan S information. Retrieved from https://docs.google.com/presentation/d/1tW846P5YCCkfzT2uu2_8QR6_XsM4A6rDTuFjm3aNL DI

LIBER Europe. (2018, December 6). LIBER Open Access Working Group: Statement on Plan S Guidelines. Retrieved January 7, 2019, from LIBER website:

https://libereurope.eu/blog/2018/12/06/liber-statement-plan-s-guidelines/

Plan S: HighWire whitepaper explores the options publishers are considering. (n.d.). Retrieved July 5, 2019, from Highwire Press website:

https://www.highwirepress.com/resources/whitepapers/plan-s-highwire/

Plan S Open Letter-Open Letter. (n.d.). Retrieved July 9, 2019, from

https://sites.google.com/view/plansopenletter/open-letter

Plan S: Provoking Discussion, Driving Change | NISO website. (n.d.). Retrieved July 5, 2019, from https://www.niso.org/niso-io/2019/04/plan-s-provoking-discussion-driving-change

Plan S will bring many changes, but the death of the repository should not be one. (2018, October 21). Retrieved January 6, 2019, from Times Higher Education (THE) website: https://www.timeshighereducation.com/blog/plan-s-will-bring-many-changes-death-repository-sh ould-not-be-one

Poynder, R. (2018, October 10). Open and Shut?: "It is for publishers to provide Plan S-compliant routes to publication in their journals." Retrieved October 15, 2018, from Open and Shut? website: https://poynder.blogspot.com/2018/10/it-is-for-publishers-to-provide-plan-s.html

Proudman, V. (2018, September 5). New coalition of European funders join together to place unprecedented mandate on researchers to publish OA [Blog]. Retrieved September 13, 2018, from SPARC Europe website:

https://sparceurope.org/new-coalition-of-european-funders-join-together-to-place-unprecedente d-mandate-on-researchers-to-publish-oa/

Publishers express concern about unintended consequences of Plan S. (n.d.). Retrieved July 5, 2019, from 
https://www.insidehighered.com/news/2019/02/19/publishers-express-concern-about-unintende d-consequences-plan-s

Quaderi, N., Hardcastle, J., Petrou, C., \& Szomszor, M. (n.d.). The Plan S footprint: Implications for the scholarly publishing landscape (p. 24). Retrieved from Institute for Scientific Information website: https://clarivate.com/g/plan-s-footprint/

Researchers' first reactions to Plan S updates. (n.d.). Retrieved July 5, 2019, from https://www.rsc.org/news-events/articles/2019/jun/plan-s-livestream/

Plan S: Academic freedom and statements of principle. Retrieved July 9, 2019, from Samuel Moore website:

https://www.samuelmoore.org/2019/03/01/plan-s-academic-freedom-and-statements-of-principle I

Open and Shut?: Why did Riksbankens Jubileumsfond decide to leave cOAlition S? Retrieved July 26, 2019, from Open and Shut? website:

https://poynder.blogspot.com/2019/06/why-did-riksbankens-jubileumsfond.html

Spotlight: Harvard Library and MIT Libraries provide recommendations for Plan S implementation | Scholarly Publishing - MIT Libraries. (n.d.). Retrieved July 5, 2019, from https://libraries.mit.edu/scholarly/2019/spotlight-harvard-library-and-mit-libraries-provide-recom mendations-for-plan-s-implementation/

The Guild: Recommendations for Open Access and the implementation of Plan S. (n.d.). Retrieved July 5, 2019, from Science|Business website:

https://sciencebusiness.net/network-news/guild-recommendations-open-access-and-implement ation-plan-s

Thoughts on Plan S First see the plan itself: COAlition S: Making Open Acc... (n.d.). Retrieved September 13, 2018, from https://plus.google.com/+PeterSuber/posts/iGEFpdYY9dr 